\title{
Effects of group size on the threat-sensitive response to varying concentrations of chemical alarm cues by juvenile convict cichlids ${ }^{1}$
}

\author{
Grant E. Brown, Tony Bongiorno, Daniel M. DiCapua, Laura I. Ivan, and Ellie Roh
}

\begin{abstract}
The threat-sensitive predator avoidance model predicts that prey should balance the intensity of antipredator responses against perceived predation risk, resulting in a graded response pattern. Recent studies have demonstrated considerable interspecific variation in the intensity of threat-sensitive response patterns, ranging from strongly graded to relatively nongraded or "hypersensitive" threat-sensitive response patterns. Here, we test for intraspecific plasticity in threat-sensitive responses by varying group size. We exposed juvenile convict cichlids, Archocentrus nigrofasciatus (Günther, 1867), as individuals or in small (groups of three) or large (groups of six) shoals to a series of dilutions of conspecific chemical alarm cues and a distilled water control. Singleton cichlids exhibited significant reductions in time spent moving and in frequency of foraging attempts (relative to distilled water controls) when exposed to a $12.5 \%$ dilution of conspecific alarm cue, with no difference in response intensity at higher stimulus concentrations, suggesting a nongraded (hypersensitive) response pattern. Small shoals exhibited a similar response pattern, but at a higher response threshold (25\% dilution of stock alarm cue solution). Large shoals, however, exhibited a graded response pattern. These results suggest that group size influences the trade-off between predator avoidance and other fitness related activities, resulting in flexible threat-sensitive response patterns.
\end{abstract}

Résumé : Le modèle d'évitement des prédateurs par sensibilité aux menaces prédit que la proie devrait ajuster l'intensité de ses réactions aux prédateurs au risque perçu de prédation, ce qui génère un pattern graduel de réactions. Des études récentes ont démontré qu'il existe une variation interspécifique considérable dans les patrons de réactions par sensibilité aux menaces, allant de patrons nettement graduels de réactions à des réactions non graduelles ou « hypersensibles ». Nous évaluons dans notre étude la plasticité intraspécifique des réactions par sensibilité aux menaces en faisant varier la taille des groupes. Nous avons exposé de jeunes cichlidés zèbres, Archocentrus nigrofasciatus (Günther, 1867), individuellement ou en petits (groupes de trois) et grands (groupes de six) bancs à une série de dilutions des signaux chimiques d'alerte de leur espèce; une exposition à l'eau distillée sert de témoin. Les poissons isolés réduisent significativement le temps passé aux déplacements ainsi que la fréquence de leurs tentatives d'alimentation (par rapport aux témoins en eau distillée) lorsqu'ils sont exposés à une dilution de $12,5 \%$ de leur signal chimique d'alerte spécifique; la réaction n'augmente pas aux plus fortes concentrations du stimulus, ce qui laisse croire que le pattern de réaction est non graduel (hypersensible). Les petits groupes de poissons ont un pattern de réactions semblable, mais à un seuil de réaction plus élevé (dilution de $25 \%$ de la solution de base du signal d'alerte). Les groupes plus considérables ont un patron de réactions graduel. Ces résultats indiquent que la taille du groupe influence le compromis entre l'évitement des prédateurs et les autres activités reliées à la fitness, ce qui entraîne des patrons flexibles de réactions par sensibilité aux menaces.

[Traduit par la Rédaction]

\section{Introduction}

Predator avoidance behaviour is shaped by a series of trade-offs between the benefits associated with the successful detection and escape from potential predators and a suite

Received 10 May 2005. Accepted 10 November 2005.

Published on the NRC Research Press Web site at

http://cjz.nrc.ca on 21 December 2005.

G.E. Brown, ${ }^{2}$ T. Bongiorno, D.M. DiCapua, L.I. Ivan, and

E. Roh. Department of Biology, Concordia University, 7141

Sherbrooke Street West, Montreal, QC H4B 1R6, Canada.

${ }^{1}$ The article is dedicated in memory of Professor Joseph A. Brown.

${ }^{2}$ Corresponding author (e-mail: gbrown@alcor.concordia.ca). of other fitness-related activities such as foraging, mating, and (or) territorial defence (Lima and Dill 1990). Helfman (1989) proposed a model of threat-sensitive predator avoidance, which argues that prey should be able to balance these trade-offs if they could adjust the intensity of the antipredator response according to the degree of perceived predation threat. By doing so, prey could retain some benefits associated with predator avoidance while still engaging in other fitness-related activities. Thus, prey capable of such threatsensitive trade-offs should be at a selective advantage (Helfman 1989; Helfman and Winkleman 1997). To date, the threat-sensitivity model has received wide support in a variety of prey taxa, including aquatic invertebrates (e.g., Scarratt and Godin 1992; Peckarsky 1996; Rochette et al. 1997), terrestrial invertebrates (e.g., Persons and Rypstra 2001; Jackson et al. 2002; Persons et al. 2002), amphibians 
Fig. 1. Theoretical extremes of threat-sensitive response patterns. Strong threat sensitivity implies that response intensity and perceived risk covary in a graded fashion. Conversely, a hypersensitive pattern implies an intense antipredator response regardless of the threat. Modified from Helfman and Winkleman (1997).

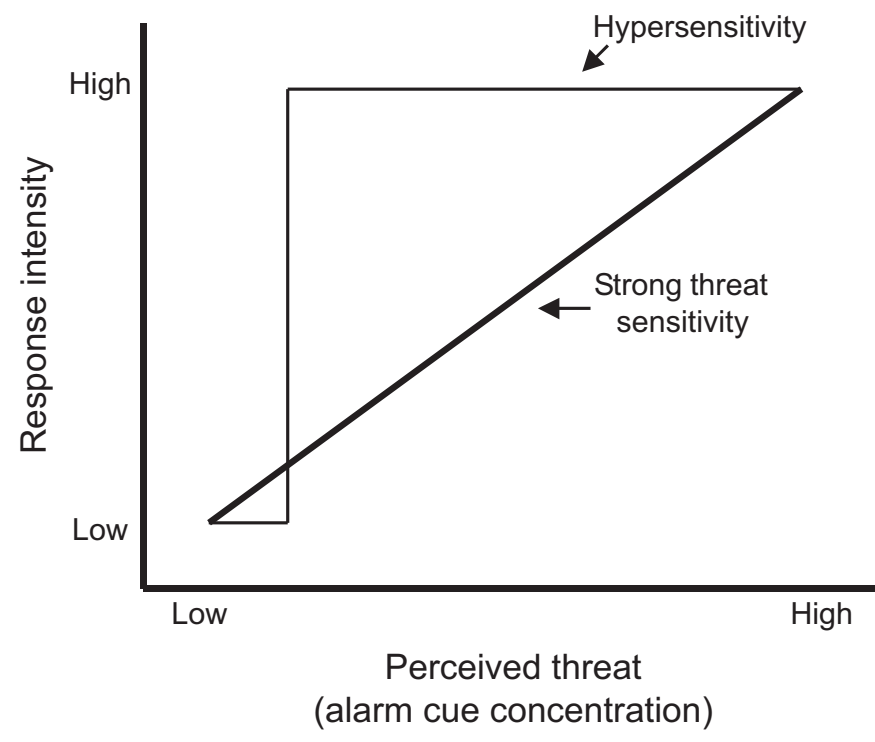

(e.g., Laurila et al. 1997; Rohr and Madison 2001), reptiles (e.g., Bulova 1994; Amo et al. 2004), birds (e.g., Lima 1992a, 1992b), and mammals (e.g., Swaisgood et al. 1999a, 1999b). In addition, several authors have demonstrated that freshwater prey fishes exposed to visual predator cues exhibit graded responses consistent with the threat-sensitivity hypothesis (Bishop and Brown 1992; Chivers et al. 2001).

Helfman and Winkleman (1997) argued that speciesspecific differences in predation risk should influence the degree of threat-sensitive response patterns. They compared the threat-sensitive response patterns of two sympatric damselfish species, the threespot damselfish (Stegastes planifrons (Cuvier, 1830)) and the bicolour damselfish (Stegastes partitus (Poey, 1868)). While both commonly co-occur on reefs, threespot damselfish are benthic territorial herbivores, while bicolour damselfish rely on a more risky planktivorous foraging strategy throughout the water column (Myrberg 1972; Helfman and Winkleman 1997). The response of juvenile threespot damselfish towards a model predator covaries with increasing perceived predation risk, suggesting a highly graded or strong threat-sensitive response pattern (i.e., graded response; Helfman and Winkleman 1997). Sympatric bicolour damselfish, however, exhibited a nongraded response pattern, showing antipredator responses at or near maximal intensities towards all model presentations, regardless of perceived predation risk. Helfman and Winkleman (1997) termed this a "hypersensitive or weak threat-sensitive response". These results demonstrate interspecific differences in the degree of threat sensitivity, likely owing to risk associated with speciesspecific foraging patterns (Helfman and Winkleman 1997). However, it remains unknown if the shape of threat-sensitive response patterns is plastic within species.

A wide variety of taxonomically diverse freshwater fishes rely on damage-released chemical alarm cues to assess local predation risk (reviewed in Chivers and Smith 1998;
Wisenden 2000). Such chemical alarm cues are released following mechanical damage to the skin, as would occur during a predation event, and can elicit dramatic short-term increases in species-typical antipredator behaviours in both conspecifics and some sympatric heterospecifics (Chivers and Smith 1998; Smith 1999). Given that relative alarm cue concentration should be directly related to proximity to a predation event, prey fishes should be able to assess local predation risk based on the concentration of alarm cue detected (Lawrence and Smith 1989; Dupuch et al. 2004).

Recent studies testing for the threat-sensitive response to varying concentrations of conspecific chemical alarm cues suggest that the form of threat-sensitive response patterns varies across prey fishes. Results consistent with graded or proportional responses to varying concentrations of conspecific alarm cues (strong threat sensitivity; Fig. 1) have been reported for northern redbelly dace (Phoxinus eos (Cope, 1861)) (Dupuch et al. 2004), roach (Rutilus rutilus (L., 1758)) (Jachner and Rydz 2002), and goldfish (Carassius auratus (L., 1758)) (Zhao and Chivers 2005). Conversely, results consistent with a nongraded or hypersensitive response pattern (Fig. 1; Helfman and Winkleman 1997) have been reported for fathead minnows (Pimephales promelas Rafinesque, 1820) (Lawrence and Smith 1989; Brown et al. 2001a), juvenile convict cichlids (Archocentrus nigrofasciatus (Günther, 1867)) (Roh et al. 2004), rainbow trout (Oncorhynchus mykiss (Walbaum, 1792)) (Mirza and Chivers 2003), and pumpkinseed (Lepomis gibbosus (L., 1758)) (Marcus and Brown 2003).

Roh et al. (2004) exposed pairs of juvenile convict cichlids to conspecific chemical alarm cues over a range of concentrations. They report that cichlids exposed to concentrations of $25 \%$ and above of a standard stock solution (diluted in distilled water) exhibited significant increases in species-typical antipredator behaviour. Pairs of cichlids exposed to $12.5 \%$ dilutions did not exhibit any antipredator response (i.e., were not different from a distilled water control). Moreover, Roh et al. (2004) demonstrate that there was no difference in the intensity of antipredator behaviour elicited by increasing concentrations of conspecific alarm cues, suggesting a nongraded response pattern.

Within aquatic vertebrate communities, it is well established that group size influences individual predation risk (Morgan and Godin 1985; Hager and Helfman 1991; Hoare et al. 2004). As such, the presence and intensity of threatsensitive predator avoidance should vary as group size changes. Thus, a potential predation cue should be treated as a higher risk by individual or small groups versus larger groups. As a result, the shape of the threat-sensitive response pattern should be influenced by the size of social aggregations detecting a predation threat. The goal of this study is to determine if shoal size, hence individual risk, influences the form of threat-sensitive responses in juvenile convict cichlids. We exposed individual or shoals of three or six juvenile cichlids, from the same laboratory population, to varying concentrations of conspecific chemical alarm cues. If threatsensitive response patterns are fixed (i.e., not plastic), then we would predict (i) similar response thresholds and (ii) similar threat-sensitive response patterns regardless of shoal size. If threat-sensitive response patterns are indeed plastic, we would predict that cichlids tested individually or in small 
shoals should exhibit nongraded (hypersensitive; Fig. 1) response patterns, similar to those reported by Roh et al. (2004). Cichlids tested in larger shoals, however, would be expected to exhibit a more graded threat-sensitive response pattern (Fig. 1).

\section{General methods}

\section{Test fish}

Juvenile cichlids were from our laboratory stock population. These fish were descendants of crosses made approximately four generations previously between laboratory stock and wild fish from Costa Rica. Prior to testing, cichlids were held in $60 \mathrm{~L}$ glass aquaria, filled with continuously filtered dechlorinated tap water $\left(26{ }^{\circ} \mathrm{C}, \mathrm{pH} \sim 7.2,12 \mathrm{~h}\right.$ light : $12 \mathrm{~h}$ dark cycle) and a gravel substrate. Cichlids were fed ad libitum twice daily with commercial flake food and brine shrimp (species of Artemia Leach, 1819).

\section{Test tanks}

Test tanks consisted of a series of $37 \mathrm{~L}$ glass aquaria, filled with $35 \mathrm{~L}$ of dechlorinated tap water $\left(25-26{ }^{\circ} \mathrm{C}, \mathrm{pH} \sim 7.2\right)$ and a gravel substrate. Test tanks were not filtered. We attached a single air stone to the rear wall of each tank. An additional $2.5 \mathrm{~m}$ length of airline tubing was attached next to the air stone to allow for the injection of stimuli without disturbing the test fish. We covered three sides of each tank to ensure visual isolation from adjacent tanks. In addition, we divided each tank into three vertical sections with lines drawn on the exterior of the tanks to facilitate the measurement of area use (see below).

\section{Stimulus preparation}

For each experiment, we generated stock alarm cue solutions. Mean \pm SD lengths of donors were $3.39 \pm 0.51(N=$ $8), 3.29 \pm 0.34(N=15)$, and $3.21 \pm 0.36(N=9)$ for experiments 1,2 , and 3 , respectively. Skin extract donor cichlids were killed with a blow to the head (in accordance with Concordia University Animal Care protocol No. AC-2002BROW). We removed skin fillets from either side of each donor fish and immediately placed them into $50 \mathrm{~mL}$ of chilled glass-distilled water. Skin fillets were then homogenized, filtered through polyester floss (to remove any remaining tissue), and diluted to the final volume with distilled water. We collected a total of $31.33 \mathrm{~cm}^{2}$ (in $350 \mathrm{~mL}$ ), $34.96 \mathrm{~cm}^{2}$ (in $392 \mathrm{~mL}$ ), and $29.19 \mathrm{~cm}^{2}$ (in $328 \mathrm{~mL}$ ) of skin for experiments 1,2 , and 3 , respectively. As a result, the initial stock concentration was similar for each experiment.

\section{Experiment 1: response of singleton cichlids}

We employed a blocked repeated-measures design to test individual responses to a distilled water control or conspecific alarm cues at each of four concentrations. Each tank received each of the five treatments, separated by $24 \mathrm{~h}$, in random order. We placed one juvenile cichlid (mean $\pm \mathrm{SD}=$ $2.95 \pm 0.12 \mathrm{~cm}$ ) into each test tank and allowed a $24 \mathrm{~h}$ acclimation period before testing. Cichlids were chosen haphazardly from the stock tanks. Approximately $1 \mathrm{~h}$ prior to testing, test fish were fed ad libitum with commercial flake food to reduce potential confounds of a foraging-antipredator tradeoff (Smith 1981; Brown and Smith 1996). Trials consisted of a 5 min pre-stimulus and a 5 min post-stimulus injection observation period. Prior to the pre-stimulus observation period, we withdrew and discarded $60 \mathrm{~mL}$ of tank water through the stimulus injection tube (to remove any residual cues from the tube). We then removed and retained an additional $60 \mathrm{~mL}$ of tank water. Following the pre-stimulus observation period, we injected $10 \mathrm{~mL}$ of distilled water (control), $10 \mathrm{~mL}$ of undiluted stock alarm cue (100\%) or $10 \mathrm{~mL}$ of alarm cue diluted to $50 \%, 25 \%$, or $12.5 \%$ of stock concentration with the addition of distilled water. Upon completion of the post-stimulus observation period, cichlids were removed from their testing tank and placed into an identical testing tank filled with fresh, dechlorinated tap water. The used test tanks were drained, cleaned, and refilled for use on the following testing day. We conducted a total of 15 replicates (i.e., 3 blocks of 5 tanks). Trials were conducted between 22 November and 20 December 2004.

During both the pre-stimulus and the post-stimulus observation periods, we quantified time spent moving and number of foraging attempts for individual cichlids. We recorded time moving as the total time, in seconds, the focal fish was not stationary. We defined foraging as pecking at the substrate, with the body at an angle greater than $45^{\circ}$ to the substrate (Grant et al. 2002). Given that cichlids were fed ad libitum prior to testing, there was always some flake food that had settled to the substrate. Reduced time spent moving and frequency of foraging attempts are indicative of an increase in antipredator behaviour in juvenile cichlids (Wisenden and Sargent 1997; Roh et al. 2004).

We then calculated the difference between the pre- and post-stimulus observation periods and used these difference scores as dependent variables in subsequent analyses. We tested for effects of alarm cue concentration using a repeatedmeasures ANOVA. Individual comparisons were made using Fisher's protected least squared differences (PLSD).

\section{Experiment 2: response of small shoals}

Mean \pm SD size at testing was $3.02 \pm 0.14 \mathrm{~cm}$. The experimental protocol was identical to that of experiment 1 , with two exceptions. First, we placed shoals of three cichlids, matched for size, into each test tank. Second, in addition to the frequency of foraging attempts, we recorded area use every $15 \mathrm{~s}$ (as opposed to time spent moving). We selected area use as a behavioural measure, because it is difficult to reliably record time moving for multiple fish. Time moving, however, was appropriate for singleton cichlids, as they were rarely observed above the substrate.

Area use was recorded by assigning each fish a score of 1 (bottom third of the tank) to 3 (top third of the tank). As such, area use scores were from 3 (all fish near the substrate) to 9 (all fish near the surface). Increase shoal cohesion and decreased area use are indicative of an antipredator response in juvenile cichlids (Wisenden and Sargent 1997; Alemadi and Wisenden 2002; Brown et al. 2004a). To make direct comparisons of foraging data, the frequency of foraging attempts is expressed as a per capita rate. Data were analyzed as described above. Cichlids were chosen haphazardly from our stock tanks. We conducted a total of 15 replicates 
(i.e., 3 blocks of 5 tanks). Trials were conducted between 10 and 31 January 2005.

\section{Experiment 3: response of large shoals}

Our experimental protocol was the same as described above for experiment 2, with the exception that area use scores were from 6 (all fish near the substrate) to 18 (all fish near the surface). Mean \pm SD size at testing was $2.92 \pm$ $0.14 \mathrm{~cm}$. As above, we conducted a total of 15 replicates (i.e., 3 blocks of 5 tanks). Trials were conducted between 7 and 28 February 2005.

\section{Results}

\section{Response of singletons}

We found significant overall effects of stimulus concentration on both change in foraging $\left(F_{[4,11]}=10.14, P=0.001\right.$; Fig. 1A) and time moving $\left(F_{[4,11]}=4.17, P=0.027\right.$; Fig. 2A). Individual cichlids exposed to conspecific alarm cues at dilutions of $12.5 \%$ and above significantly decreased the number of foraging attempts and time spent moving compared with the distilled water control. We found no significant differences between the four dilutions of alarm cues (Figs. 2A, 3A). These data, thus, are consistent with a nongraded or hypersensitive threat-sensitive response pattern (Helfman and Winkleman 1997).

\section{Response of small shoals}

We found significant overall effects of stimulus concentration on change in per capita foraging attempts $\left(F_{[4,11]}=\right.$ 20.81, $P<0.0001$; Fig. 2B) and on change in area use $\left(F_{[4,11]}=7.52, P=0.004\right.$; Fig. $\left.3 \mathrm{~B}\right)$. For each measure, there was no significant change in response to the distilled water control or the $12.5 \%$ dilution of alarm cue. However, when exposed to conspecific alarm cue at dilutions of $25 \%$ and above, trios of cichlids exhibited significant decreases in frequency of foraging and area use and significantly increased shoal cohesion. As for singleton cichlids, these data are consistent with a nongraded response pattern.

\section{Response of large shoals}

We found significant overall effects of stimulus concentration on change in per capita foraging attempts $\left(F_{[4,11]}=\right.$ 10.52, $P=0.001$; Fig. 2C) and on change in area use $\left(F_{[4,11]}=5.12, P=0.014\right.$; Fig. 3C $)$. However, unlike the response patterns for singleton and small shoals, the responses of large shoals appear to be graded (Figs. 2C, 3C).

As an additional comparison, we calculated the proportional change in foraging rates (post-stimulus rate $\times$ poststimulus rate $^{-1}$ ). We used proportional change in foraging rates, versus per capita foraging rates, because the baseline foraging was markedly lower in small and large shoals than in singletons. This decrease in overall foraging rate is likely due to competition within groups (Kim et al. 2004). We plotted mean proportional change for each experiment against stimulus concentration and tested for difference in slopes using an ANCOVA. We found a significant interaction between stimulus concentration and group size $\left(F_{[4,38]}=3.49\right.$, $P=0.016$; Fig. 4). While not conclusive, as this analysis represents a comparison of data collected over three separate
Fig. 2. Mean $( \pm \mathrm{SE})$ change in number of foraging attempts for singleton cichlids, Archocentrus nigrofasciatus, (A) or per capita foraging attempts for small shoals (B) or large shoals (C) of cichlids exposed to each of the alarm cue dilutions and the distilled water (DW) control. $N=15$ for each group of cichlids and different letters denote significant differences at $P<0.05$, based on Fisher's PLSD tests.
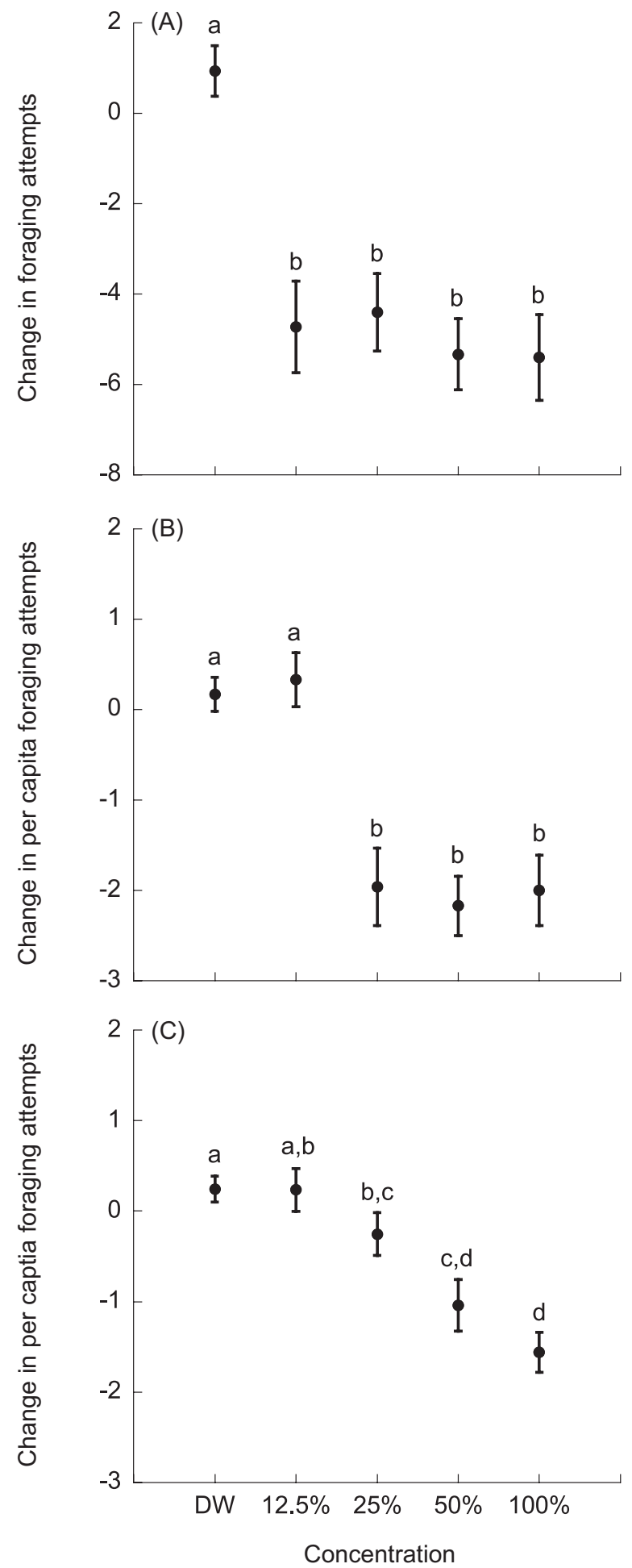
Fig. 3. Mean $( \pm \mathrm{SE})$ change in time spent moving for singleton cichlids (A) or change in area use for small shoals (B) or large shoals (C) of cichlids exposed to each of the alarm cue dilutions and the distilled water (DW) control. $N=15$ for each group of cichlids and different letters denote significant differences at $P<$ 0.05, based on Fisher's PLSD tests.
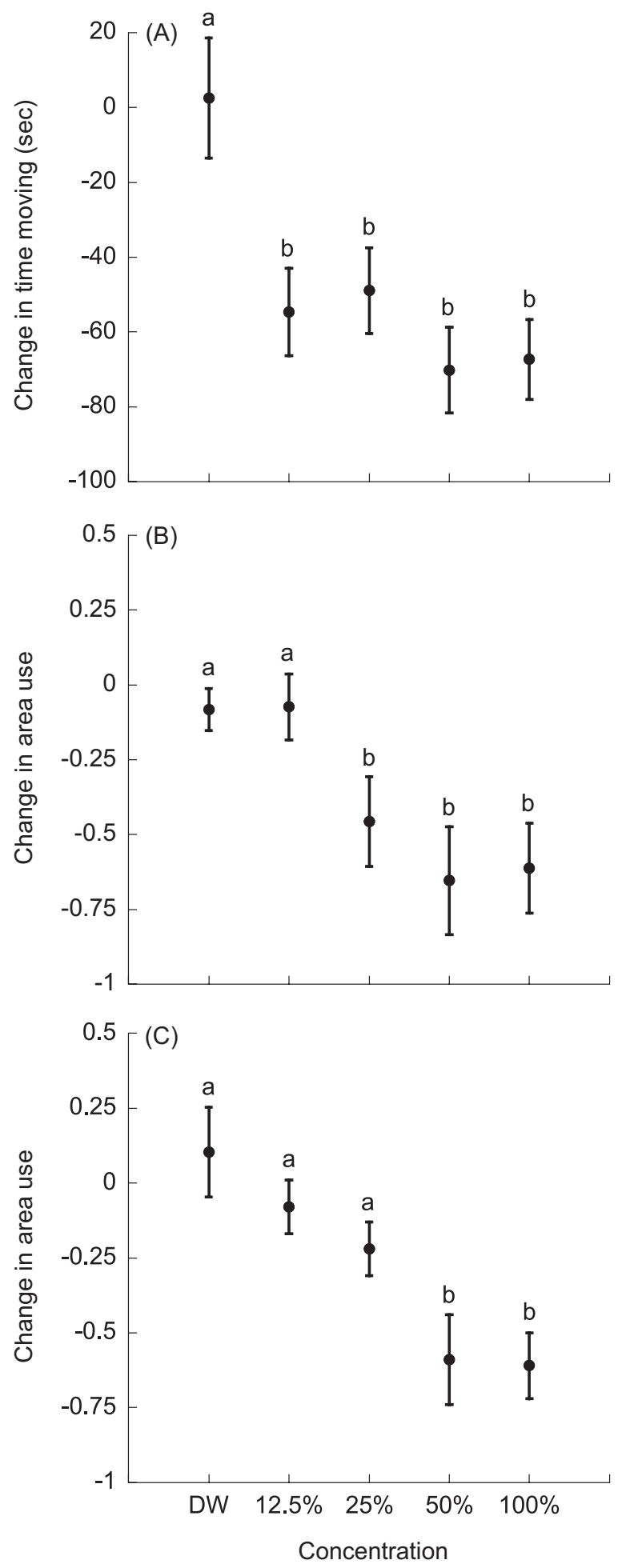

Fig. 4. Mean $( \pm \mathrm{SE})$ proportional change in number of per capita foraging attempts for singleton cichlids (circles, solid line), small shoals (squares, large broken line), or large shoals (triangles, small broken line) of cichlids exposed to each of the alarm cue dilutions and the distilled water (DW) control.

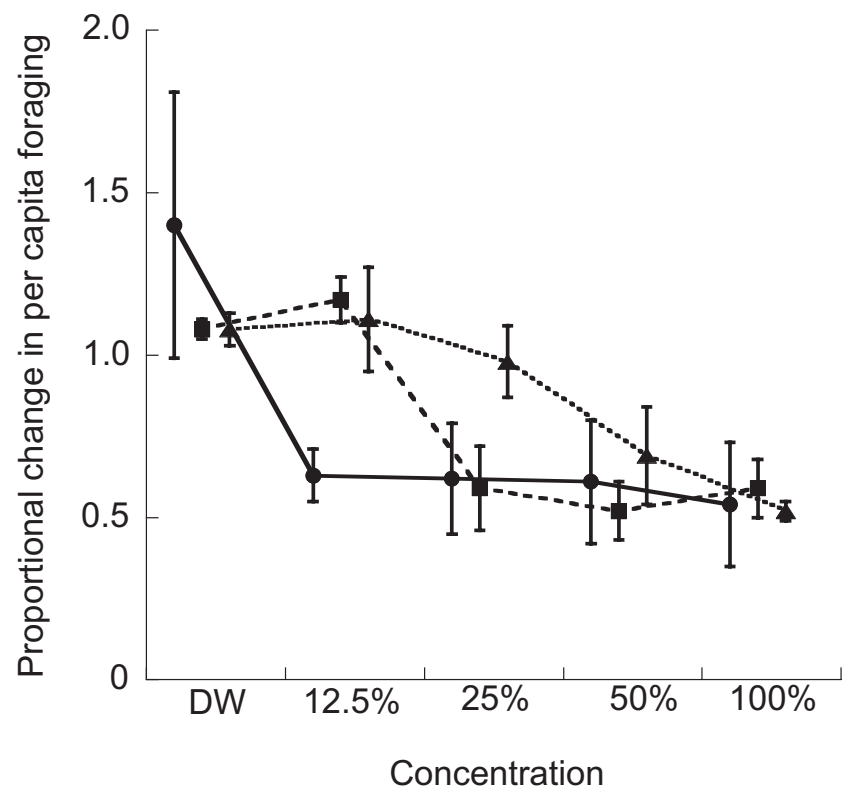

experiments, it does suggest that the shapes of the threatsensitive response patterns were indeed different.

\section{Discussion}

These data demonstrate that the shape of the threat-sensitive response pattern (hence intensity of threat sensitivity; Helfman and Winkleman 1997) of juvenile convict cichlids is influenced by group size. Solitary cichlids exhibited a significant increase in antipredator behaviour at the lowest concentration of alarm cue tested (12.5\%). At concentrations of $12.5 \%$ and above, solitary cichlids exhibited a hypersensitive (nongraded) response pattern. Shoals of three cichlids exhibited a similar response pattern, except that the concentration needed to elicit any response was greater than $12.5 \%$. Finally, shoals of six cichlids exhibited an increase in antipredator behaviour consistent with a graded (strong threat sensitivity) response pattern.

The shape of the threat-sensitive response curve is dictated by the relative benefits of predator avoidance versus those obtained through continued foraging or some other fitness-related activity (Helfman and Winkleman 1997). Accordingly, under conditions of low perceived risk, prey should be expected to exhibit a less intense antipredator response, as the benefits associated with continued foraging would outweigh those associated with predator avoidance. However, under conditions of higher perceived predation threats, the trade-off should shift in favour of predator avoidance, and prey should therefore exhibit an intense antipredator response. Our current data suggest that group size influences the shape of the threat-sensitive response pattern by altering the relative benefits associated with predator avoidance. The trade-off between antipredator and foraging benefits for singleton cichlids versus larger shoals would 
likely be very different, as singletons or those in small shoals would have reduced predator avoidance benefits associated with group membership (Hoare et al. 2004). Thus, singletons and small groups appear more willing to trade off potential foraging benefits in favour of a hypersensitive antipredator response, while those in larger shoals exhibit strong threat-sensitive responses.

Recent studies demonstrate that prey fishes can detect conspecific alarm cues well below the concentration required to elicit overt antipredator responses (Brown et al. 2001b; Mirza and Chivers 2003). For example, fathead minnows acquire the recognition of novel predator cues when paired with alarm cues well below the population-specific behavioural response threshold (Brown et al. 2001b). Juvenile rainbow trout gain increased survival benefits during encounters with a live predator when exposed to sub-threshold concentrations of conspecific alarm cues (Mirza and Chivers 2003). In addition, recent studies suggest that prey individuals may exhibit subtle changes in a suite of behavioural patterns in the absence of typical overt antipredator response, including changes in foraging posture (Foam et al. 2005), increased inspection and (or) exploratory behaviour (e.g., Lawrence and Smith 1989; Jachner and Rydz 2002), and increased vigilance towards conspecific visual alarm displays (Brown et al. 2004b). Though untested, it is likely that prey in larger shoals may increase their use of these types of "risk aversive" behaviours, allowing for more graded threat-sensitive response patterns.

Direct comparisons among studies examining the threatsensitive responses to varying concentrations of alarm cues in prey fishes are difficult because of a number of methodological differences. Initially, the range of concentrations of alarm cues tested varies between studies. For example, the highest concentration tested by Jachner and Rydz (2002) was a full order of magnitude lower than that tested by Lawrence and Smith (1989). As such, this limited concentration range may influence the shape of the final response pattern. Secondly, some studies have tested for concentration effects by making between-group (concentrations) statistical comparisons (i.e., Brown et al. 2001a; Mirza and Chivers 2003), while others made within-group comparisons and tested for graded responses using correlation analyses (i.e., Jachner and Rydz 2002; Dupuch et al. 2004). Although both are statistically valid, they might lead to very different conclusions. The most notable difference, however, is the use of different experimental shoal sizes. For example, studies with roach (Jachner and Rydz 2002) and northern redbelly dace (Dupuch et al. 2004) showed strong threat-sensitive responses when testing shoals of 5 or 10 , respectively. Conversely, studies showing nongraded threat-sensitive responses have typically tested single individuals (fathead minnows, Lawrence and Smith 1989; rainbow trout, Mirza and Chivers 2003) or relatively small shoal sizes (cichlids, Roh et al. 2004; pumpkinseed, Marcus and Brown 2003; fathead minnows, Brown et al. 2001a).

A number of other factors may likewise influence the shape of the threat-sensitive response pattern exhibited by prey fishes. It is well established that a variety of factors influence the intensity of antipredator responses in prey fishes, including ambient predation pressure (Brown et al. 2001b), individual hunger levels (Smith 1981; Brown and Smith
1996; Chivers et al. 2000), learning (Kelley and Magurran 2003), familiarity and (or) relatedness among group members (Chivers et al. 1995; Ward and Hart 2003; Hoare et al. 2004), ontogeny (Chivers et al. 2001; Golub and Brown 2003), and availability of additional information (Brown and Godin 1999; Smith and Belk 2001). These factors may influence the trade-off between the benefits associated with continued foraging and predator avoidance. As such, factors that increase potential foraging benefits relative to antipredator benefits (i.e., increased hunger level, stable social groups, high visibility conditions) should be expected to result in stronger threat-sensitive response patterns. Conversely, factors that decrease foraging benefits relative to antipredator benefits (i.e., high predation pressure, unfamiliar shoalmates) should result in a less graded threat-sensitive pattern. Further experiments are required to test these predictions.

\section{Acknowledgements}

We thank James Grant, Mark Harvey, Antoine Leduc, and Isabelle Désormeaux for helpful comments on the manuscript. Financial support was provided by Concordia University and by the Natural Sciences and Engineering Research Council of Canada to G.E.B. All work reported herewithin was conducted in accordance with Concordia University Animal Care protocol No. AC-2002-BROW.

\section{References}

Alemadi, S.D., and Wisenden, B.D. 2002. Antipredator response to injury-released chemical alarm cues by convict cichlid young before and after independence from parental protection. Behaviour, 139: 603-611.

Amo, L., Lopez, P., and Martin, J. 2004. Wall lizards combine chemical and visual cues of ambush snake predators to avoid overestimating risk inside refuges. Anim. Behav. 67: 647-653.

Bishop, T.D., and Brown, J.A. 1992. Threat sensitive foraging by larval threespine sticklebacks (Gasterosteus aculeatus). Behav. Ecol. Sociobiol. 31: 133-138.

Brown, G.E., and Godin, J.-G.J. 1999. Who dares, learns: chemical inspection behaviour and acquired predator recognition in a characin fish. Anim. Behav. 57: 475-481.

Brown, G.E., and Smith, R.J.F. 1996: Foraging trade-offs in fathead minnows (Pimephales promelas): acquired predator recognition in the absence of an alarm response. Ethology, 102: 776-785.

Brown, G.E., Adrian, J.C., Jr., and Shih, M.L. 2001a. Behavioural responses of fathead minnows (Pimephales promelas) to hypoxanthine-3- $N$-oxide at varying concentrations. J. Fish Biol. 58: $1465-1470$

Brown, G.E., Adrian, J.C., Jr., Patton, T., and Chivers, D.P. $2001 b$. Fathead minnows learn to recognize predator odour when exposed to concentrations of artificial alarm pheromones below their behavioural response thresholds. Can. J. Zool. 79: 22392245.

Brown, G.E., Foam, P.E., Cowell, H.E., Guevara-Fiore, P., and Chivers, D.P. 2004a. Production of chemical alarm cues in juvenile convict cichlids: the effect of diet, condition, and ontogeny. Ann. Zool. Fenn. 41: 487-499.

Brown, G.E., Poirier, J.-F., and Adrian, J.C., Jr. 2004b. Assessment of local predation risk: the role of subthreshold concentrations of chemical alarm cues. Behav. Ecol. 15: 810-815. 
Bulova, S.J. 1994. Ecological correlates of population and individual variation in antipredator behavior of 2 species of desert lizards. Copeia, 1994: 980-992.

Chivers, D.P., and Smith, R.J.F. 1998. Chemical alarm signaling in aquatic predator-prey systems: a review and prospectus. Ecoscience, 5: 338-352.

Chivers, D.P., Brown, G.E., and Smith, R.J.F. 1995. Familiarity and shoal cohesion in fathead minnows (Pimephales promelas): implications for anti-predator behaviour. Can. J. Zool. 73: 955960.

Chivers, D.P., Puttlitz, M.H., and Blaustein, A.R. 2000. Chemical alarm signaling by reticulate sculpins (Cottus perplexus). Environ. Biol. Fishes, 57: 347-352.

Chivers, D.P., Mirza, R.S., Bryer, P.J., and Kiesecker, J.M. 2001. Threat-sensitive predator avoidance by slimy sculpins: understanding the importance of visual versus chemical information. Can. J. Zool. 79: 867-873.

Dupuch, A., Magnan, P., and Dill, L.M. 2004. Sensitivity of northern redbelly dace, Phoxinus eos, to chemical alarm cues. Can. J. Zool. 82: 407-415.

Foam, P.E., Harvey, M.C., Mirza, R.S., and Brown, G.E. 2005. Heads up: juvenile convict cichlids switch to threat-sensitive foraging tactics based on chemosensory information. Anim. Behav. 70: 601-607.

Golub, J.L., and Brown, G.E. 2003. Are all signals the same? Ontogenetic changes in the response to conspecific and heterospecific alarm signals by juvenile green sunfish (Lepomis cyanellus). Behav. Ecol. Sociobiol. 54: 113-118.

Grant, J.W.A., Girard, I.L., Breau, C., and Weir, L.K. 2002. Influence of food abundance on competitive aggression in juvenile convict cichlids. Anim. Behav. 63: 323-330.

Hager, M.C., and Helfman, G.S. 1991. Safety in numbers: shoal size choice by minnows under predator threat. Behav. Ecol. Sociobiol. 29: 271-276.

Helfman, G.S. 1989. Threat-sensitive predator avoidance in damselfish-trumpetfish interactions. Behav. Ecol. Sociobiol. 24: 47-58.

Helfman, G.S., and Winkelman, D.L. 1997. Threat sensitivity in bicolor damselfish: effects of sociality and body size. Ethology, 103: 369-383.

Hoare, D.J., Couzin, I.D., Godin, J.-G.J., and Krause, J. 2004. Context-dependent group size choice in fish. Anim. Behav. 67: 155-164.

Jachner, A., and Rydz, M.A. 2002. Behavioural response of roach (Cyprinidae) to different doses of chemical alarm cues (Schreckstoff). Arch. Hydrobiol. 155: 369-381.

Jackson, R.R., Pollard, S.D., Li, D.Q., and Fijn, N. 2002. Interpopulation variation in the risk-related decisions of Portia labiata, an araneophagic jumping spider (Areneae, Salticidae), during predator sequences with spitting spiders. Anim. Cogn. 5: 215-223.

Kelley, J.L., and Magurran, A.E. 2003. Learned predator recognition and antipredator responses in fishes. Fish Fish. 4: 216-226.

Kim, J.W., Brown, G.E., and Grant, J.W.A. 2004. Interactions between patch size and predation risk affect competitive aggression and size variation in juvenile convict cichlids. Anim. Behav. 68: 1181-1187.

Laurila, A., Kujasalo, J., and Ranta, E. 1997. Different antipredator behaviour in two anuran tadpoles: effects of predator diet. Behav. Ecol. Sociobiol. 40: 329-336.

Lawrence, B.J., and Smith, R.J.F. 1989. Behavioral response of solitary fathead minnows, Pimephales promelas, to alarm substance. J. Chem. Ecol. 15: 209-219.
Lima, S.L. 1992a. Strong preferences for apparently dangerous habitats: a consequence of differential escape from predators. Oikos, 64: 597-600.

Lima, S.L. 1992b. Vigilance and foraging substrate: antipredatory considerations in a nonstandard environment. Behav. Ecol. Sociobiol. 30: 283-289.

Lima, S.L., and Dill, L.M. 1990. Behavioral decisions made under the risk of predation: a review and prospectus. Can. J. Zool. 68: 619-640.

Marcus, J.M., and Brown, G.E. 2003. Response of pumpkinseed sunfish to conspecific chemical alarm cues: an interaction between ontogeny and stimulus concentration. Can. J. Zool. 81: 1671-1677.

Mirza, R.S., and Chivers, D.P. 2003. Response of juvenile rainbow trout to varying concentrations of chemical alarm cue: response thresholds and survival during encounters with predators. Can. J. Zool. 81: 88-95.

Morgan, M.J., and Godin, J.-G.J. 1985. Antipredator benefits of schooling behaviour in a cyprinodontid fish, the banded killifish (Fundulus diaphanous). Z. Tierpsychol. 70: 236-246.

Myrberg, A.A., Jr. 1972. Ethology of the bicolor damselfish, Eupomacentrus paritus (Pisces: Pomacentridae): a comparative analysis of laboratory and field behavior. Anim. Behav. Monogr. 5: 197-283.

Peckarsky, B.L. 1996. Alternative predator avoidance syndromes of stream-dwelling mayfly larvae. Ecology, 77: 1888-1905.

Persons, M.H., and Rypstra, A.L. 2001. Wolf spiders show graded antipredator behavior in the presence of chemical cues from different sized predators. J. Chem. Ecol. 27: 2493-2504.

Persons, M.H., Walker, S.E., and Rypstra, A.L. 2002. Fitness costs and benefits of antipredator behavior mediated by chemotactile cues in the wolf spider Pardosa milvina (Araneae: Lycosidae). Behav. Ecol. 13: 386-392.

Rochette, R., Dill, L.M., and Himmelman, J.H. 1997. A field test of threat sensitivity in a marine gastropod. Anim. Behav. 54: 1053-1062.

Roh, E., Mirza, R.S., and Brown, G.E. 2004. Quality or quantity? The role of donor condition in the production of chemical alarm cues in juvenile convict cichlids. Behaviour, 141: 1235-1248.

Rohr, J.R., and Madison, D.M. 2001. A chemically mediated tradeoff between predation risk and mate search in newts. Anim. Behav. 62: 863-869.

Scarratt, A.M., and Godin, J.-G.J. 1992. Foraging and antipredator decisions in the hermit crab, Pagurus acadianus (Benedict). J. Exp. Mar. Biol. Ecol. 156: 225-238.

Smith, M.E., and Belk, M.C. 2001. Risk assessment in western mosquitofish (Gambusia affinis): do multiple cues have additive effects? Behav. Ecol. Sociobiol. 51: 101-107.

Smith, R.J.F. 1981. Effect of food deprivation on the reaction of Iowa darters (Etheostoma exile) to skin extract. Can. J. Zool. 59: 558-560.

Smith, R.J.F. 1999. What good is smelly stuff in the skin? Cross function and cross taxa effects in fish "alarm substances". In Advances in chemical signals in vertebrates. Edited by R.E. Johnston, D. Müller-Schwarze, and P.W. Sorensen. Kluwer Academic, New York. pp. 475-488.

Swaisgood, R.R., Owings, D.H., and Rowe, M.P. 1999a. Conflict and assessment in a predator-prey system: ground squirrels versus rattlesnakes. Anim. Behav. 57: 1033-1044.

Swaisgood, R.R., Rowe, M.P., and Owings, D.H. 1999b. Assessment of rattlesnake dangerousness by California ground squirrels: exploitation of cues from rattling sounds. Anim. Behav. 57: 1301-1310. 
Ward, A.J.W., and Hart, P.J.B. 2003. The effects of kin and familiarity on interactions between fish. Fish Fish. 4: 348-358.

Wisenden, B.D. 2000. Scents of danger: the evolution of olfactory ornamentation in chemically-mediated predator-prey interactions. In Animal signals: signalling and signal design in animal communication. Edited by Y. Espmark, T. Amundsen, and G. Rosenqvist. Tapir Academic, Trondheim, Norway. pp. 365-386.

Wisenden, B.D., and Sargent, R.C. 1997. Antipredator behavior and suppressed aggression by convict cichlids in response to injury-released chemical cues of conspecifics but not those of an allopatric heterospecific. Ethology, 103: 283-291.

Zhao, X., and Chivers, D.P. 2005. Response of juvenile goldfish (Carassius auratus) to chemical alarm cues: relationship between response intensity, response duration and the level of predation risk. In Chemical signals in vertebrates. Vol. 10. Edited by R.T. Mason, M. LeMaster, and D. Müller-Schwarze. SpringerVerlag, New York. pp. 334-341. 